\title{
The multi-purpose greenways network planning in the Taichung Metropolitan Area, Taiwan
}

\author{
S.-W. Huang \& K.-W. Tsou \\ Department of Urban Planning, National Cheng Kung University, \\ Taiwan
}

\begin{abstract}
Nowadays, most people believe that the greenway-system planning is one of the strategies to develop a sustainable city. However, most metropolitan areas are over-developed; there are no massive undeveloped areas left to create greenways. Under these circumstances, we propose redeveloping the current inter-city transportation system to create greenways, which meet the needs of ecological protection, recreation, and transportation. This research emphasizes on the Taichung Metropolitan Area (TMA), Taiwan. We first develop an assessment tool which includes GIS mapping techniques and an indicator valuation system to select appropriate roads from the current transportation system to create greenways. The indicator valuation system contains a series of indicators to evaluate the efficiency of each road in terms of 3 purposes: ecological protection, recreation, and transportation. The analyses reveal that 10 roads meet 3 purposes and 14 roads meet 2 purposes. We further apply the GIS grid technique to connect these roads to create the greenway network for the TMA. In summary, this paper develops a procedure to create the metropolitan greenway network to satisfy the multi-purposes of the public.
\end{abstract}

Keywords: multi-purpose greenways, GIS.

\section{Introduction}

With the popular conception of sustainable development, several research projects on greenway system planning had been undertaken, but most of these efforts concentrated on non-urban land, and had not addressed the metropolitan area that is already prosperous and highly development. Although greenway 
system planning is one of the strategies necessary to establish a sustainable metropolitan area, it lacked the physical planning result due to the limited amount of research about greenway system planning in the metropolitan area and the complicated spatial development structure. As a result, the impetus and practice in sustainable development in the metropolitan area has been seriously affected.

Once considered to be just a vegetated linear area for protected purposes, greenways have developed a resource that can satisfy the public's needs for ecological protection, recreation, and transportation. However, present development in the metropolitan area shows that most land has been urbanized, and it is difficult to find massive and proper undeveloped land for greenways in urban regions. To solve this difficulty, this article adopts an innovative viewpoint of multipurpose theory, concentrating on the characteristics of the metropolitan area development and conducts three purposes of greenway system including ecological protection, recreation, and transportation. It establishes a new evaluation framework using a GIS technique, adopts location decision theory and a special multiple criteria evaluation method, and tries to provide a suitable substitute project for a multipurpose greenway system. In order to cater for the plan of location decision, it not only integrates and applies the correlative information of National Geographic Information System in Taiwan, but also several distinctive geographic databases are created in the process of research.

In this paper, three principal analyses are proposed. The first, addresses patches to estimate the value of green resources, so we must establish an index system of green resource assessment and the result will be regarded as an assessable indicator of greenway planning. Second, we devise an assessable multi-purpose indicator system for including ecological protection, recreational tourism, and communications and transportation for greenway planning. In this process, we used the calculating and map overlap technique of GIS to assist these scenarios in estimating the value of greenways and selecting the suitable sections of the road. Finally, we confirmed the accuracy for the metropolitan greenway networks of ecological protection, recreation, and transportation by GIS grid technique. The main objective of the paper is to contribute a method to establish greenway systems, providing an assessable process of multi-purpose greenway planning for further research, essential in this field.

\section{Measure the green resources of patch}

In the concept of landscape ecology, the characteristics of resources within the patch usually influence the path of corridor planning. Then we estimated the value of green resources for all plots in the metropolitan area first, and used this to produce one of the greenway assessment indicators. The green resource was an extensive concept, which includes all green areas in the environment divided into ecological green spaces, productive green spaces and life green spaces according to functional property of the green spaces.

Some scholars observed the green resources with the viewpoint of land-use concept, they defined that the land isn't developed and has plants [1]. But we 
hope the green resources not only provide the use for humans but also supply habitats for wildlife and can provide relaxation, recreation and ecologic protection to improve the efficiency in the metropolitan area. So we consider the multi-propose concept to define the green resource, it was a piece of land as open space, having a plant covering, or having the potential to develop the habitat in the urban area.

In this paper, we referred to the literature to decide on the indicators for assessed the green resource. These indicators were origins, area, green cover ratio, perimeter-area ratio, resistant value of landscape and value of recreation [4-9]. The calculation value of every indicator had be normalized and then added. The description and calculation of indicators is provided in table 1.

Table 1: $\quad$ Assessment indicators of the green resources.

\begin{tabular}{|c|c|c|}
\hline Indicators & Description & Score \\
\hline \multirow{2}{*}{ Origins } & Natural & 1 \\
\hline & Cultural & 2 \\
\hline Area & Patch size & normalized score \\
\hline Green cover ratio & $\begin{array}{l}\text { (Greenery coverage area/whole } \\
\text { area) } \times 100 \%\end{array}$ & normalized score \\
\hline Perimeter-area ratio & $($ Perimeter/area $) \times 100 \%$ & normalized score \\
\hline \multirow{5}{*}{$\begin{array}{l}\text { Resistant value of } \\
\text { landscape }\end{array}$} & $\begin{array}{l}\text { Deciduous forest, mixed forest, } \\
\text { coniferous forest }\end{array}$ & 5 \\
\hline & Shrubbery, grassland, rangeland & 4 \\
\hline & Agriculture & 3 \\
\hline & Building area, mining area & 2 \\
\hline & Roads, railways, rivers & 1 \\
\hline \multirow{4}{*}{ Value of recreation } & Open space, rangeland & 4 \\
\hline & Agriculture, woodland & 3 \\
\hline & Park, playground, school & 2 \\
\hline & Building area & 1 \\
\hline
\end{tabular}

\section{Assessment of multi-purpose greenway network}

It is accepted that the greenways networks in the urban area can increase the efficiency and value of green resources in the metropolitan area [6]. Due to the difficulty of obtaining land in the metropolitan area, many cities adopted the multi-purpose strategy to plan its transportation systems gradually; the greenway had become a resource to fit in with the demand for ecological protection, recreation, and transportation [3]. The multi-purpose greenways in this paper were those that used an existing road system to assessed and selected the high-score section of road by the function of ecological protection, recreation, and transportation, and established three different scenarios with GIS techniques. In these three scenarios, the eco-greenways could be considered with the high value of green resources and the eco-resources of roads, and the path taken by animals; the recreation greenways could address the relation between roads and 
scenic spots, the graceful scenery on the road, and to benefit tourism; the transportation greenways could also affect the service and transportation. The description of indicators are provided in table 2 .

Table 2: $\quad$ The assessment indicator system of multi-purpose greenways.

\begin{tabular}{|c|c|c|}
\hline Purposes & Indicators & Criterions of assessment \\
\hline \multirow{4}{*}{$\begin{array}{l}\text { Ecological } \\
\text { protection }\end{array}$} & $\begin{array}{l}\text { The value of green } \\
\text { resources }\end{array}$ & $\begin{array}{l}\text { Total value of green resource that } \\
\text { connected with road }\end{array}$ \\
\hline & Diversity of greenery & $\begin{array}{l}\text { The number of greenery } \\
\text { classification at the road }\end{array}$ \\
\hline & $\begin{array}{l}\text { The pressure of } \\
\text { animals penetrability }\end{array}$ & $\begin{array}{l}\text { Level 1: freeway } \\
\text { Level 2: main road } \\
\text { Level 3: secondary road }\end{array}$ \\
\hline & $\begin{array}{l}\text { Green cover ratio of } \\
\text { the road }\end{array}$ & $\begin{array}{l}\text { The number of plant in one section } \\
\text { of road } \times \text { the average of the tree- } \\
\text { crown area }) /(\text { road length } \times \text { road } \\
\text { width })\end{array}$ \\
\hline \multirow{4}{*}{ Recreation } & $\begin{array}{l}\text { Scenic spots } \\
\text { connection }\end{array}$ & $\begin{array}{l}\text { Calculate the number of scenic spots } \\
\text { that connect by one section of road }\end{array}$ \\
\hline & $\begin{array}{l}\text { Green resource } \\
\text { connection }\end{array}$ & $\begin{array}{l}\text { Calculate the number of green } \\
\text { resource that connect by one section } \\
\text { of road }\end{array}$ \\
\hline & Scenic Road & Yes or no \\
\hline & Pavement & Yes or no \\
\hline \multirow{4}{*}{ Transportation } & Level of the road & $\begin{array}{l}\text { Level 1: neighbourhood road } \\
\text { Level 2: civic road } \\
\text { Level 3: interstate road } \\
\text { Level 4: national road }\end{array}$ \\
\hline & $\begin{array}{l}\text { Level of service of } \\
\text { the road }\end{array}$ & $\begin{array}{l}\text { Level 1: level F } \\
\text { Level 2: level E } \\
\text { Level 3: level D } \\
\text { Level 4: level C } \\
\text { Level 5: level B } \\
\text { Level 6: level A }\end{array}$ \\
\hline & Fast traffic lane & $\begin{array}{l}\text { Calculate the number of fast traffic } \\
\text { lane }\end{array}$ \\
\hline & $\begin{array}{l}\text { Near bus stop or } \\
\text { train station }\end{array}$ & $\begin{array}{l}\text { The number of bus stop and train } \\
\text { station in the designated area }\end{array}$ \\
\hline
\end{tabular}

It is necessary to use weighted indicators when producing an integral valuation, because the indicators have different importance. In this paper, we adopted the Analytic Hierarchy Process (AHP) method by using expert questionnaires to search the weight of indicators. The result of questionnaires found that the ecological protection purpose had the highest weight and the 
transportation purpose had the lowest weight in those three multi-purposes. In the section of indicators "green cover ratio of the road" had the highest weight in the ecological protection purpose, meaning that this indicator was very important for ecological protection. On the other hand, "scenic spots connection" was the most influence to recreation and "level of the road" was the most influence to transportation. Other weights of the indicators are displayed in table 3 . In the multi-purpose application, the policymakers can adjust the weight in order to increase the significance of a factor they are concerned with. For example, if we want to increase the significance of the ecological protection purpose, we can increase the weight of ecological protection indicators and then we can get a multi-purpose greenway network relying mainly on ecological protection.

Table 3: $\quad$ The weight of multi-purpose greenway assessment system.

\begin{tabular}{|c|c|}
\hline Purposes & Indicators (weight) \\
\hline \multirow{4}{*}{ Ecological protection $(0.36)$} & The value of green resources $(0.10)$ \\
\hline & Diversity of greenery $(0.07)$ \\
\hline & The pressure of animals penetrability $(0.06)$ \\
\hline & Green cover ratio of the road $(0.13)$ \\
\hline \multirow{4}{*}{ Recreation $(0.34)$} & Scenic spots connection $(0.11)$ \\
\hline & Green resource connection $(0.06)$ \\
\hline & Scenic Road $(0.10)$ \\
\hline & Pavement $(0.07)$ \\
\hline \multirow{4}{*}{ Transportation $(0.30)$} & Level of the road $(0.11)$ \\
\hline & Level of service of the road $(0.05)$ \\
\hline & Fast traffic lane $(0.05)$ \\
\hline & Near bus stop or train station $(0.09)$ \\
\hline
\end{tabular}

After the above process, we can know the three different scores of every section of road in the present transportation system, but it was usually an untidy map like figure 2. So we apply the GIS grid technique-selecting the highest score grid in the neighbourhood to connect these roads to create the greenway network. This is illustrated with case study below.

\section{Case study}

The Tai-Chung Metropolitan Area is one of the most densely populated areas of Taiwan. There are about $250 \mathrm{~km}^{2}$ and 1.5 million people; it currently has a density of 6000 inhabitants $/ \mathrm{km}^{2}$, and has a percentage of population growth of $1.18 \%$, it has heavy pressure of population aggregation. Typically, municipal land use and urban plans do not take into consideration functional ecological processes and, as a result, there are not enough open spaces to provide a green environment and increase quality of life. Consequently, this is a significant factor in the multi-purpose planning for the use of the road. 


\subsection{The result of green resource assessment}

The first section of multi-purpose plan has assessed the green resources. We put the data of indicators in table 1 to calculate the value of green resources with equal weight. The result of the values in the TMA, the higher lever patch distributed over the suburban area and the lower lever patch massed near the city centre. That was because the patches in the suburban area have less interference from human activity than city centre. If we consider the development of a green resource, we must think about the efficient planning for urban life at the section of resource limitation. In order to increase efficiency, this paper will select highscore patches to connect in the further plan of greenway network.

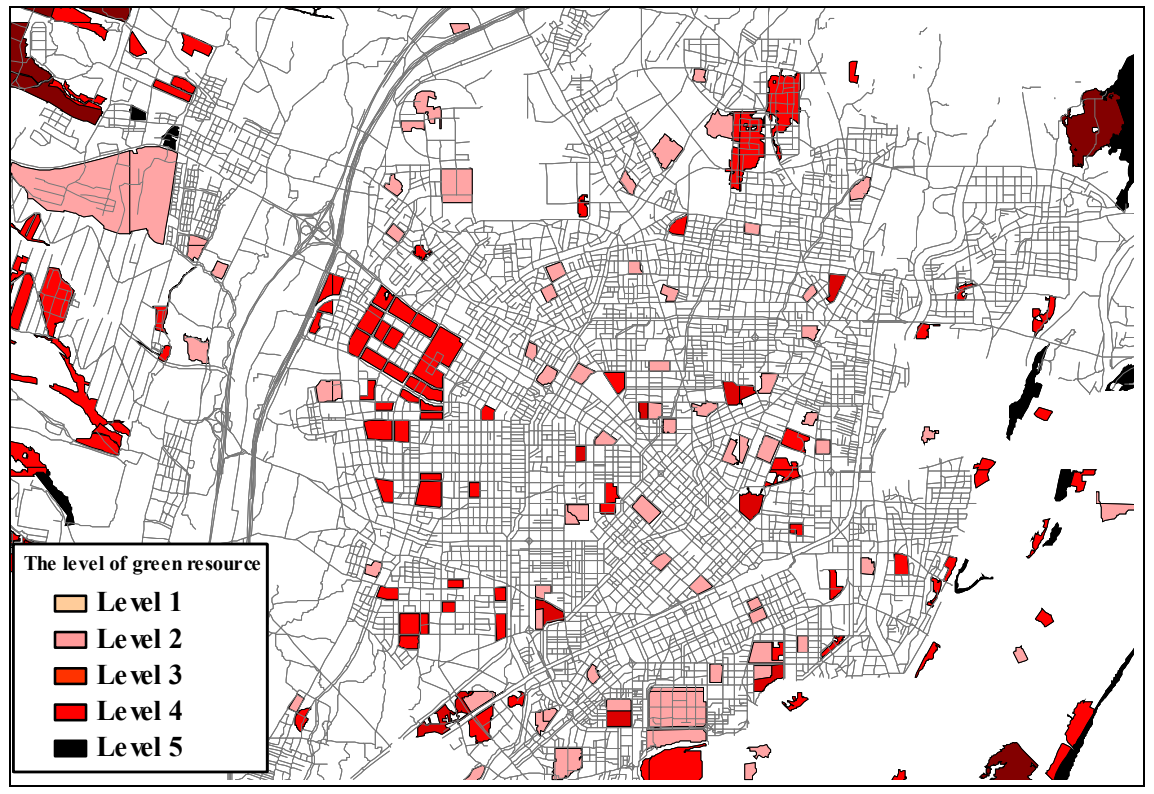

Figure 1: The level of the value of green resources.

\subsection{Multi-purpose greenway systems}

The second section involved greenways assessment. For each purpose, we magnified the weight of the most significant purpose two times, and then we can obtain a new weighted matrix (table 4). First, we relied mainly on eco-development, so we magnified the weight of each indicator of ecological protection two times, and normalized all indicators. After this process, we can get three new weights: $0.53,0.25$, and 0.22 respectively. Second, we showed the result on a spatial map by GIS (figure 2), and use a GIS grid technique to 
connect these roads to create the ecological protection greenway network (figure 3). In the same way, we show the recreation greenway network and transportation greenway network on figure 4 and figure 5.

Table 4: The new weight of multi-purpose greenway assessment system after normalized.

\begin{tabular}{|l|r|r|r|}
\hline \multicolumn{1}{|c|}{ Purposes } & $\begin{array}{c}\text { Relying mainly on } \\
\text { eco-development }\end{array}$ & $\begin{array}{c}\text { Relying mainly on } \\
\text { recreation } \\
\text { development }\end{array}$ & $\begin{array}{c}\text { Relying mainly on } \\
\text { transportation } \\
\text { development }\end{array}$ \\
\hline $\begin{array}{l}\text { Ecological protection } \\
(0.36)\end{array}$ & 0.53 & 0.27 & 0.28 \\
\hline Recreation $(0.34)$ & 0.25 & 0.51 & 0.26 \\
\hline Transportation $(0.30)$ & 0.22 & 0.22 & 0.46 \\
\hline
\end{tabular}

The indicator valuation system contains a series of indicators to evaluate the efficiency of each road in terms of 3 purposes: ecological protection, recreation, and transportation. The analyses reveal that 26 roads were selected in the ecological protect scenario, 32 roads were selected in the recreation scenario, 24 roads were selected in the transportation scenario, 10 roads meet 3 scenarios and 14 roads meet 2 scenarios.

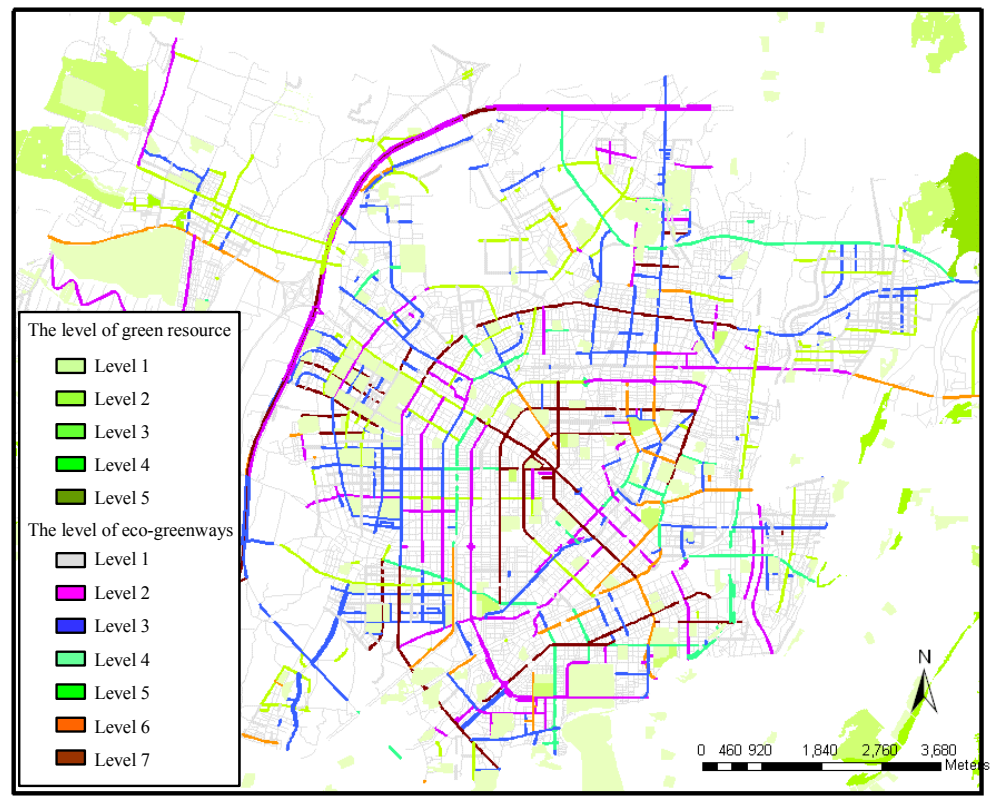

Figure 2: $\quad$ The scores of every road in the ecological protection scenario. 


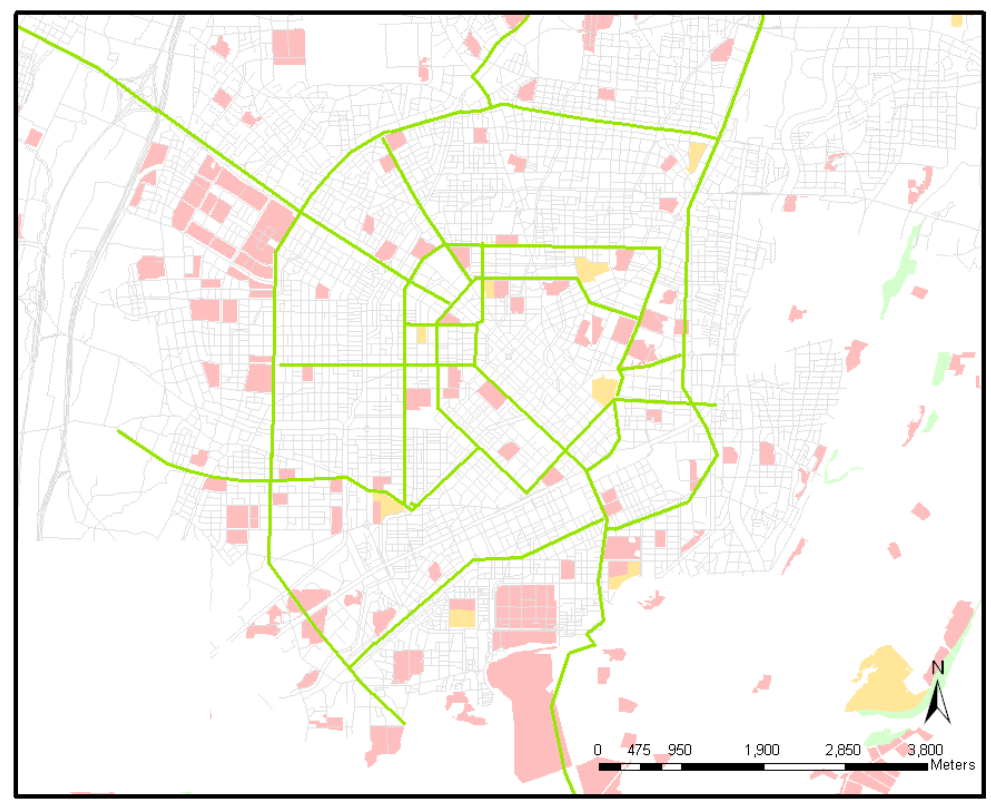

Figure 3: The greenway network of ecological protection scenario.

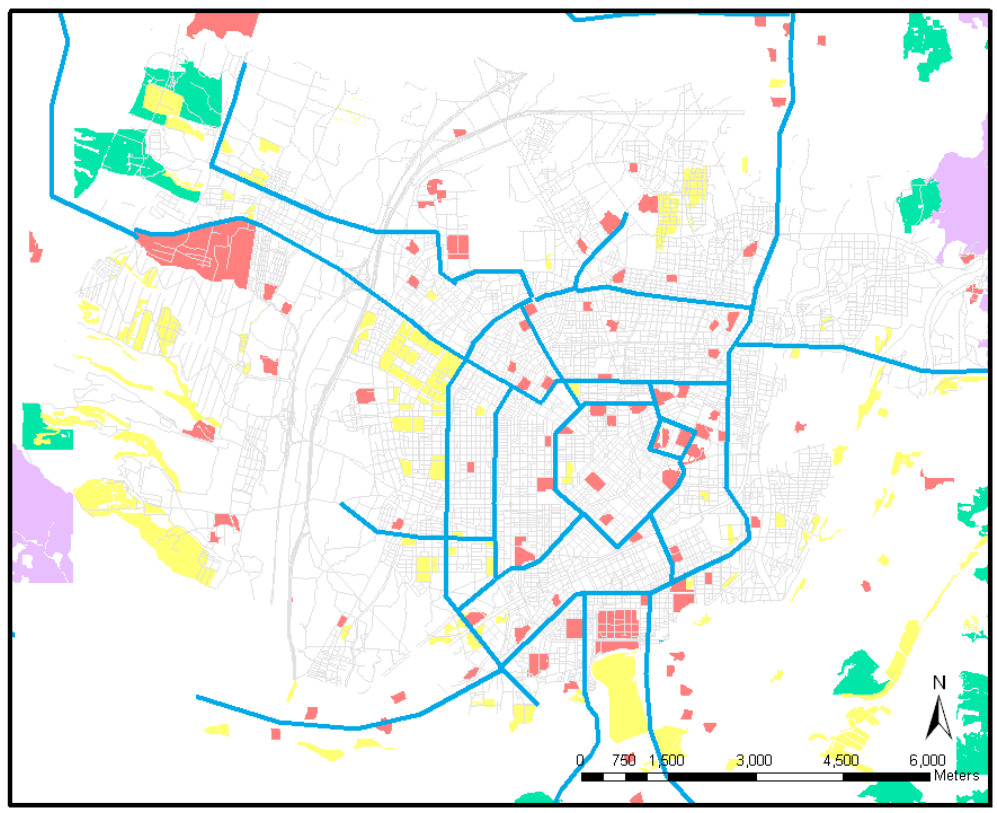

Figure 4: The greenway network of recreation scenario. 


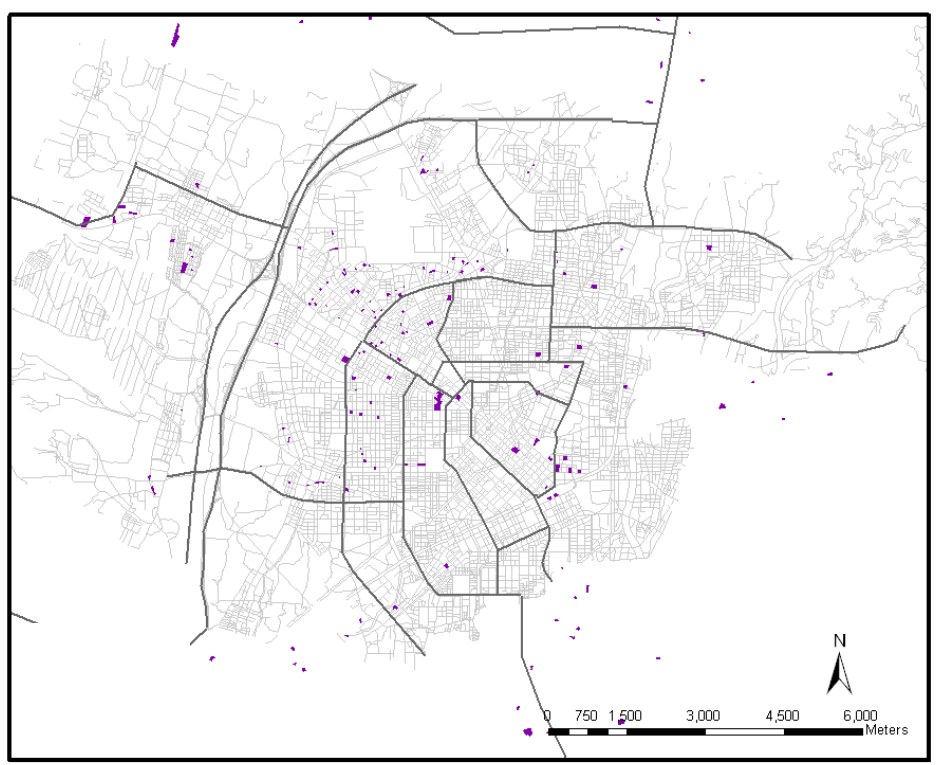

Figure 5: The greenway network of transportation scenario.

\section{Conclusions}

According a literature review of the greenway researches, most research has previously focused on a single purpose to plan the eco-greenways, they usually thought about the life and migration of the animals, and not to consider the use of human. Besides, in many cases, the study areas were usually in the rural area, and the civic area is not studied in detail. For this reason, this paper tried to establish a greenway system that can be used with human and animals together in the metropolitan area, to develop the divers demands and improved the limitation of a single function.

Currently, urban greenway plans sometimes meet the troubles with regards to technical operation and assessable procedure. We attempted to use the spatial display and grid technique of GIS to select the high-score roads automatically, providing a fast and efficient way to reduce the waste of manpower and material resources. This paper adopted a multi-purpose method and provided three scenarios, the policymaker can think about the direction of urban development to establish the transportation system that fitted the demand for development. This introduced a degree of elasticity into the planning process.

\section{References}

[1] Ahern J. (1991), Planning for an extensive open space system: linking landscape structure and function, Landscape and Urban Planning, Vol.21, pp.131-145. 
[2] Ahern, J., (1995), Greenways as an planning strategy, Landscape and Urban Planning, Vol.33, pp.131-155.

[3] Conine, A., Xiang, W.N., Young, J., Whitley, D., (2004). Planning for multi-purpose greenways in Concord, North Carolina, Landscape and Urban Planning, Vol. 68, pp. 271-287.

[4] Cook, E. A., (1991), Urban landscape networks: an ecological planning framework, Landscape Res. Vol. 16(3), pp.7-15.

[5] Cook, E. A., (2002), Landscape structure indices for assessing urban ecological networks, Landscape and Urban Planning, Vol. 58, pp. 269-180.

[6] Forman, R.T.T., Gordon, M., (1986), Landscape Ecology, New York: John Wiley \& Sons.

[7] Forman, R. T. T. (1995), Land Mosaics: The ecology of landscapes and regions. New York: Cambridge University Press.

[8] Forman, R.T.T., (1995), Some general principles of landscape and regional ecology, Landscape Ecology, Vol.10 (3), pp.133-142.

[9] Knaapen, J.P., Scheffer, M., Harms, W.B.,(1992), Estimating habitat isolation in landscape planning . Landscape and Urban Planning, Vol.23, pp.1-16. 